\title{
Sugarcane/Sugarcane Juice Quality Evaluation by FT-NIR Spectrometer
}

\author{
Sonal Tripathi ${ }^{1}$, Narendra Singh ${ }^{2 *}$, Shailesh Mali ${ }^{3}$, J.R. Naik ${ }^{1}$ and S. Mistry Pritesh ${ }^{1}$ \\ ${ }^{1}$ Department of Soil Science and Agricultural Chemistry, Navsari Agricultural University- \\ Navsari-396 450, Gujarat, India \\ ${ }^{2}$ Directorate of Extension Education, Navsari Agricultural University \\ Navsari-396 450, Gujarat, India \\ ${ }^{3}$ Main Sugarcane Research Station, Navsari Agricultural University, \\ Navsari 396 450, Gujarat, India \\ *Corresponding author
}

\section{A B S T R A C T}

A simple method using Fourier Transform Near-Infrared (FT-NIR) was investigated to determine quality of sugarcane/sugarcane juice in terms of brix value (total soluble solids), sucrose content (polarization \%) and purity. Correlation equations for the

\section{Keywords}

Sugarcane, Sugarcane juice, Quality, FT-NIR, Brix, Sucrose content.

\section{Article Info}

Accepted:

28 August 2017 Available Online: 10 September 2017 chemometric models to predict the quality parameters of sugarcane juice were developed using partial least square (PLS) regression and were evaluated by cross validation and external test set validation to test their reliability for the calculation of ${ }^{\circ}$ brix (TSS), sucrose content and purity. The PLS regressions were performed on NIR spectra in the range of 9997.7 to $5774.1 \mathrm{~cm}^{-1}$. This spectral region was further divided into two interactive spectral regions from wavenumber 9997.7 to $7498.3 \mathrm{~cm}^{-1}$ and 6102 to $5774.1 \mathrm{~cm}^{-1}$. The prediction models developed were checked by cross validation to test its reliability. The root means square errors for cross validation (RMSECV) and correlation coefficients $\left(\mathrm{R}_{\mathrm{cv}}^{2}\right)$ were 0.0783 and 99.78 for ${ }^{\circ}$ brix, 0.258 and 98.78 for sucrose content 1.05 and 95.3 for purity. The root means square errors of prediction (RMSEP) of test samples were $0.0851,0.319$ and 0.962 , whereas the determination coefficients $\left(\mathrm{R}_{\text {val }}^{2}\right)$ for prediction were 99.7, 97.82 and 96.05 for ${ }^{\circ}$ brix, sucrose content and purity respectively. High values of determination coefficients $\left(\mathrm{R}^{2}\right)$ and low values of root mean square errors indicate high predictive accuracy of optimized models. Thus the FT-NIR offers a viable alternative for the quality evaluation of sugarcane/sugarcane juice.

\section{Introduction}

Agriculture is one of the most significant sectors of the Indian Economy. It is the only means of living for almost two thirds of the workers in India. The agriculture sector has occupied $43 \%$ of India's geographical area, and is contributing $14 \%$ of India's GDP [1].

Sugarcane is an important commercial crop of the world. India ranks second among the sugarcane growing countries of the world in both area and production after Brazil. The production of sugarcane was 3345.41 lakh tonnes with the area of 50.85 lakh hectares and the productivity was about $65.7 \mathrm{t} / \mathrm{ha}$ in the year 2012-13. Gujarat occupied the 127.50 lakh tonnes of sugarcane production with 2.02 lakh hectare area and $63.1 \mathrm{t} / \mathrm{ha}$ productivity in the year 2012-13. Among this more than 90 
per cent area and production of sugarcane was recorded in the South Gujarat region of Gujarat state [2]. The sugarcane cultivation and sugar industries in India play a vital role towards socio-economic development in the rural areas by mobilizing rural resources and generating higher income and employment opportunities. About 7.5 percent of the rural population, covering about 45 million sugarcane farmers, their dependents and a large number of agricultural labour are involved in sugarcane cultivation, harvesting and ancillary activities [3].

The quality of sugarcane and sugarcane juice is evaluated in terms of ${ }^{\circ}$ brix (total soluble solid), polarizable sugar (sucrose content) and purity percent. The parameters mentioned above are estimated by measurement with refractometer and polarimeter respectively, as standard methodologies that are regulated by norms of evaluation of the quality of sugarcane [4]. Brix can be defined as the percentage in weight, or in volume, of soluble solids expressed as sucrose. In sugar cane juice it is a quantitative measurement of the total solids (including sugars), not giving any qualitative information about which sugars are present in the final product [5]. Polarizable sugar (POL) is a measurement of the amount of sucrose in the mixture of sugars, because in it, only sucrose diverts the plane of polarized light [6]. The traditional method of sugarcane juice quality analysis is tedious and time consuming. Alternative methods of such as mid infrared spectroscopy and fluorescence have been investigated and tested, with the aim to increase the reliability, uniformity of the method and the accuracy of the measurements [7, 8]. Near infrared spectroscopy (NIR) has been recently investigated as an alternative methodology, due its special characteristics such as nondestructivity, quickness and no production of offensive wastes $[9,10]$.

The major strengths of FT-NIR include fast and easy equipment operation, high accuracy, precision and the potential to perform nondestructive analysis. Therefore it was thought worthwhile to develop a simple and non-destructive FT-NIR method for analysis of quality parameters (total soluble solids, sucrose content, purity) of sugarcane juice.

\section{Materials and Methods}

\section{Sample preparation and analysis}

One twenty six samples of different sugarcane genotypes were obtained from Regional Sugarcane Research Station, Navsari. These samples were crushed to obtain sugarcane juice. The samples of cane juice were initially cleared with lead sub-acetate $\left(\mathrm{Pb}\left(\mathrm{CH}_{3} \mathrm{COO}\right)_{2}\right.$. $\left.\mathrm{Pb}(\mathrm{OH})_{2}\right)$ and filtered. The brix value and sucrose content (pol) in the calibration samples were analyzed using ${ }^{\circ}$ Brix refractometer (Rudolph Research, J15, Germany) and digital polarimeter (Rudolph Research, Autopol 880, Germany) respectively. The purity was calculated as percentage ratio of sucrose to the total soluble solids [4]. The 'brix, and sucrose content ranged from 12.7 to 20.97 and 9.87 to 20.72 respectively, while purity percentage varied from 74.58 to 86.45 in calibration set of samples (Table 1).

\section{FT-NIR instrument}

The FT-NIR spectrometer (Bruker Optics, MPA, Germany) used for the study was capable of measurements in transmission mode in sample compartment. The PbS detector $\left(12,500\right.$ to $\left.4000 \mathrm{~cm}^{-1}\right)$ was used for analyzing the samples.

\section{Spectra acquisition}

The NIR spectra of sugarcane juice samples were collected in the transmission mode using FT-NIR spectrometer with a sample 
compartment in the range of $4000-12500 \mathrm{~cm}^{-1}$ wave numbers. The sample vials, $(40 \mathrm{~mm} \mathrm{X}$ $8.2 \mathrm{~mm}$ ) filled with sugarcane juice were kept in the sample compartment. For each calibration standard, the spectrum was attained by averaging three spectral scans.

The room temperature was kept around $25^{\circ} \mathrm{C}$ and the humidity was at steady level of 58 $60 \%$ in the laboratory.

\section{Data analysis}

Acquired spectra were analyzed by Quant 5.5 software. As the samples were containing several components in the matrix, thus the spectra will show considerable overlap bands. Therefore, multivariate calibration was used which correlates considerably more spectral information using larger spectral range with reference value of calibration set. This leads to a higher degree of precision with reduced chances of errors [11]. Partial least square (PLS) regression was used to correlate data in spectra matrix with the data in the concentration matrix for developing calibration model to determine the brix, sucrose content and purity. The samples (126) were divided in the two sets, viz., calibration sample and test set validation sample randomly, and each set containing 63 samples. The matrixes were reduced to only a few factors using all the available information to avoid over fitting of the model. The quality of the calibration models for prediction of ${ }^{\circ}$ brix, sucrose content and purity were checked by cross validation as well as test set validation of these models.

\section{Results and Discussion}

\section{NIR spectrum}

The spectra of sugarcane juice samples, ranged between 4000 to $12800 \mathrm{~cm}^{-1}$ wave numbers were shown in figure 1 . The spectral responses contain the absorption information of many hydrocarbon groups in the clarified juice samples, such as sucrose, organic acids, amino acids etc. The absorption due to water molecules was observed around $5492 \mathrm{~cm}^{-1}$, and the absorption other than water appeared in the region of $5982-6000 \mathrm{~cm}^{-1}$ and $7096-$ $8820 \mathrm{~cm}^{-1}$. For improving the chemo-metric models, it was necessary to focus the PLS regression on groups that contain significant information for the system, so interactive frequency regions were selected to improve the calibration models. The region above $9997.7 \mathrm{~cm}^{-1}$ did not contain any useful information. In addition, we limited the wavenumber range to $5774.1 \mathrm{~cm}^{-1}$ because below this value there was not any spectral information. This spectral region was further divided into two interactive spectral regions of wavenumber 9997.7 to $7498.3 \mathrm{~cm}^{-1}$ and 6102 to $5774.1 \mathrm{~cm}^{-1}$ (Fig. 2). Different spectra algorithms like vector normalization, multiplicative scattering correction, min-max normalization, constant offset elimination, straight line subtraction, first derivative and second derivative were used for preprocessing of spectra and to enhance reproducibility of calibration model. The spectra of all samples were almost parallel (Fig. 2), which indicated linear response of the instrument along with sample concentrations within the range of study. Similar spectral responses were obtained for determining the sweetness of orange juice in terms of total soluble solids [12] for determination of curcuminoids from turmeric powder [13] and for quality of sugarcane juice using FT-NIR [14].

\section{Calibration and cross-validation}

The number of samples used in the calibration set, test set and statistical summary of laboratory determined brix value, sucrose content and purity is given in table 1. The PLS regressions were performed on spectra in the range of 9997.7 to $5774.1 \mathrm{~cm}^{-1}$. The 
regression method assumes that systemic variations observed in the spectra are a consequence of the concentration change of sucrose in the sample. The spectral matrix and data matrix are broken into their eigenvectors, which are called factors or principal components. The advantage of this approach was that not all of the principal components were necessary to describe. Only the relevant principal components were then be used instead of the original spectral data and then system was analyzed for each component spectra to identify the group of most effective wavelength for the prediction of sucrose content in the sugarcane juice sample. The chemometric models developed, were evaluated by cross validation to test its reliability of calculation of brix (TSS), sucrose content (POL \%) and purity. The root mean square errors of cross validation (RMSECV) were found to be 0.0783 for brix, 0.258 for sucrose content and 1.05 for purity. The correlation coefficients $\left(\mathrm{R}_{\mathrm{cv}}^{2}\right)$ were found to be 99.78 for brix, 98.78 for sucrose content and 95.3 for purity. The root means square errors of prediction (RMSEP) of test set samples were $0.0851,0.319$ and 0.962 , whereas the determination coefficients $\left(\mathrm{R}^{2}{ }_{\text {val }}\right)$ for prediction were 99.7, 97.82 and 96.05 for brix, sucrose content and purity respectively. The quality of calibration models were quantified by RMSECV and $\mathrm{R}_{\mathrm{cv}}^{2}$ value. The $\mathrm{R}^{2}$ val provided the percentage of variance present in the true value of TSS, sugar content and purity, which were reproduced in the regression. The higher values of correlation coefficient represented better correlation between the concentration data and spectral data. Figure 3 shows the diagrammatic representation of the validation results. The straight line represented that the predicted values lied close to the true value. The calibration models developed were used to predict the TSS, sucrose content and purity in 63 test set validation samples that had not been included in the calibration set.

Table.1 Calibration and prediction values of ${ }^{\circ}$ brix (TSS), sucrose content (POL) and Purity of sugarcane juice

\begin{tabular}{lcccccc}
\hline & \multicolumn{2}{c}{ Brix (TSS) } & \multicolumn{2}{c}{ Sucrose content (pol) } & \multicolumn{2}{c}{ Purity } \\
\cline { 2 - 7 } Samples Number & Calibration & Prediction & Calibration & Prediction & Calibration & Prediction \\
\cline { 2 - 7 } Minimum (\%) & 63 & 63 & 63 & 63 & 63 & 63 \\
Maximum (\%) & 12.7 & 13.11 & 9.87 & 10.59 & 74.58 & 75.04 \\
Mean (\%) & 20.97 & 20.68 & 20.72 & 20.50 & 93.63 & 93.06 \\
SD & 17.72 & 17.74 & 16.49 & 16.44 & 86.45 & 86.33 \\
\hline
\end{tabular}

$\mathrm{SD}=$ standard deviation of the reference method values

Table.2 Calibration and test set validation of ${ }^{\circ}$ brix (TSS), sucrose content (POL) and Purity of sugarcane juice

\begin{tabular}{lccc}
\hline & ${ }^{\circ}$ Brix & Sucrose content (pol) & Purity \\
\cline { 2 - 4 } $\mathbf{R}^{\mathbf{2}}$ cv & 99.78 & 98.78 & 95.3 \\
$\mathbf{R M S E C V ~}_{\mathbf{R}^{2}}{ }_{\text {val }}$ & 0.0783 & 0.258 & 1.05 \\
RMSEP $^{2}$ & 99.7 & 97.82 & 96.05 \\
\hline
\end{tabular}

$\mathrm{R}_{\mathrm{cv}}^{2}=$ determination coefficient of cross validation; $\mathrm{RMSECV}=$ Root mean square error of cross validation; $\mathrm{R}^{2}{ }_{\mathrm{val}}=$ determination coefficient of external validation; RMSEP= Root mean square error of prediction 
Fig.1 FT NIR spectra of sugarcane juice

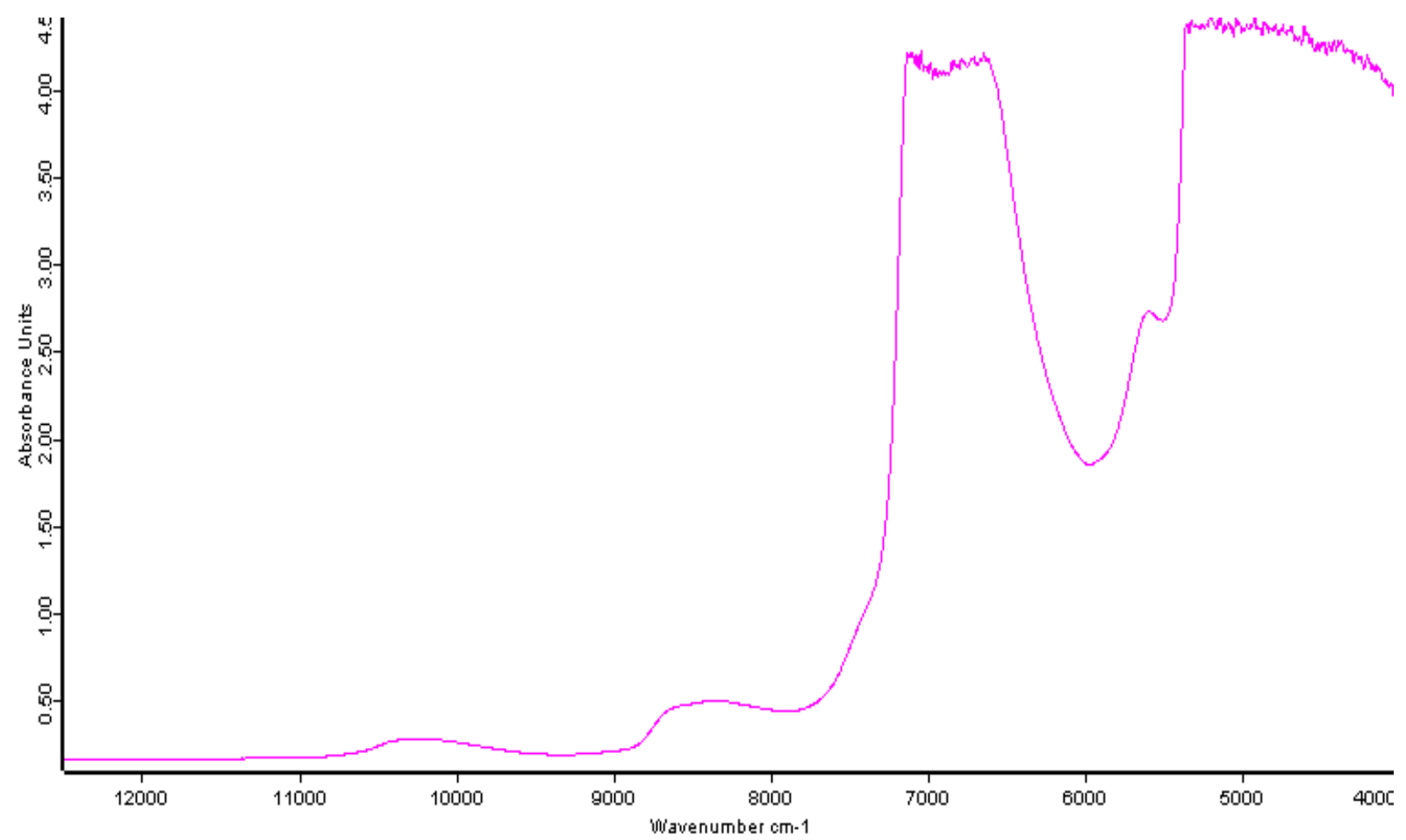

Fig.2 Diffuse reflectance NIR spectra of sugarcane juice sample showing Interactive spectral regions

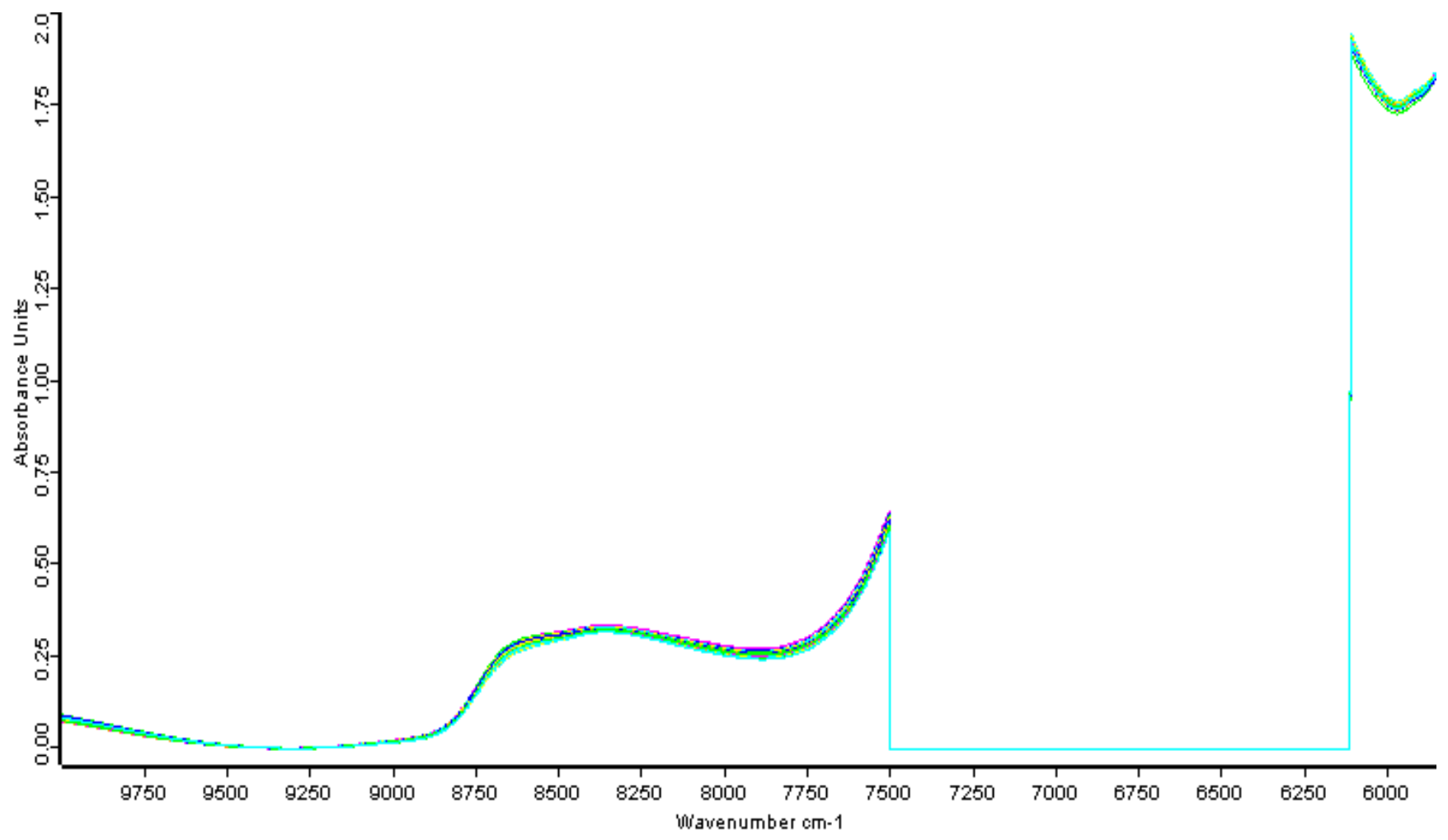


Fig.3 Scatter plot of actual Vs NIR predicted ${ }^{\circ}$ brix [a], sucrose content [b] and purity [c] in Test set of sugarcane juice samples. $\mathrm{R}^{2}$ val= determination coefficient of external validation; $\mathrm{RMSEP}=$ Root mean square error of prediction .

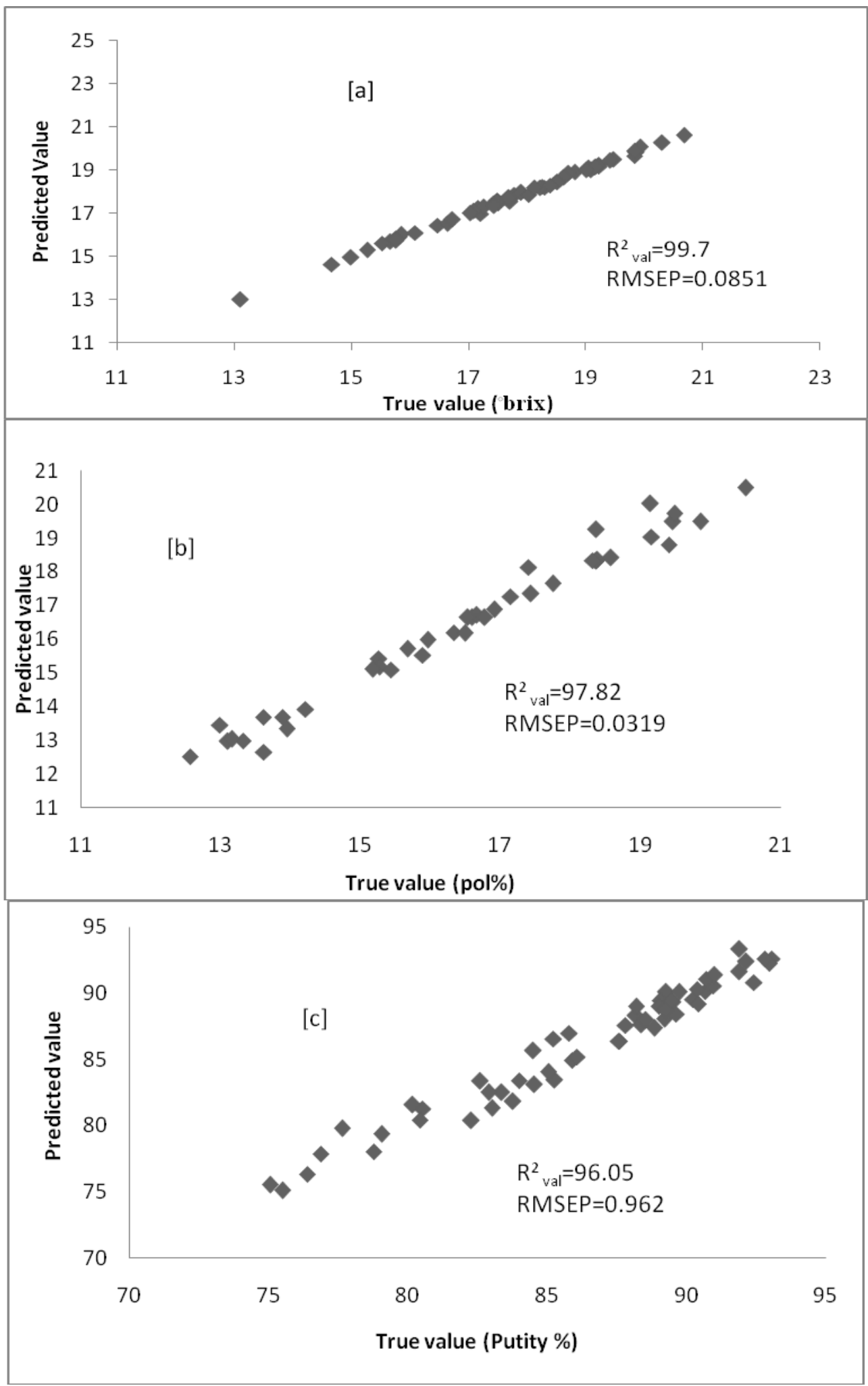


Determination coefficients $\left(\mathrm{R}^{2}\right)$ indicated a strong relationship between predicted value and actual value of TSS, sucrose content and purity (Fig. 3). This technique has been standardized for the determination of various parameters including sweetness of orange juice [12], tetracycline in milk [15], determination of curcuminoid content in turmeric [13] and lignin content in Acacia spp. [16].

The FT-NIR is user friendly, speedy, cost effective, non-destructive and therefore offers a viable alternative to traditional procedures. The calibration models were developed obtaining feasible and acceptable results. The prediction errors obtained for BRIX, POL and for purity were lower than claimed at regulated norm. The higher values of correlation coefficients represented that the predicted values lied close to the true value. Thus this technique can be applied for screening of sugarcane with varieties advantages of simultaneous determination of BRIX, POL and purity with the same NIR spectra. The accuracy and precision of the results were comparable to the standard method. A reliable overall characterization of a food product quality may be obtained at a low cost. It may be applied to the quality control, process monitoring and rapid classification in the industry.

\section{Authors' contributions}

All authors contributed equally to the study design. ST, NS, SM, JRN and PSM were involved in collection and processing of samples as well as their analysis, interpretation of results and preparation of the paper. All authors read and approved the final manuscript.

\section{Acknowledgement}

We would like to thank Dean of N.M. College, Navsari Agricultural University,
Navsari, India and Central Instrumentation Laboratory, Navsari Agricultural University, Navsari, for providing necessary requirements in conducting the research work. The support is gratefully acknowledged.

\section{References}

1. Government of India. (2016). State of Indian Agriculture 2015-16, Ministry of Agriculture \& Farmers Welfare Department of Agriculture, Cooperation \& Farmers Welfare Directorate of Economics and Statistics, New Delhi.

2. Parmar V. N., Patel, K. S. and Pandya, C. D. (2015) Trends in Biosciences, 8(6) 1509-1514.

3. Makandar N. M. and Yuvaraj P. (2015) Tactful Management Research Journal, 3(12), 1-12.

4. Bureau of Sugar Experiment Stations (BSES) (1970) Laboratory Manual for Queensland Sugar Mills (5th Ed.), Division of Mill technology, Brisbane, Queensland, Australia, 5, 95-98 and 113114

5. Valderrama P., Braga J. W. B., and Poppi R. J. (2007) Journal of the Brazilian Chemical Society, 18 (2), 259266.

6. George, P. M. (1963) Cane Sugar Handbook. A Manual for Cane sugar Manufacturers and their Chemists, John Wiley \& Sons Inc.: New York, London, Sydney.

7. Cadet F., Bertrand D., Robert P., Maillot J., Dieudonne J. and Rouch, C. (1991) Applied Spectroscopy, 45 (2), 166-172.

8. Baunsgaard D., Norgaard L. and Godshall M. A. (2000) Journal of Agricultural and Food Chemistry 48, 4955-4962.

9. Salgo A., Nagy J., Miko E. (1998) Journal of Near Infrared Spectroscopy, 6, 101-107.

10. Johnson T. P. (2001) International Sugar Journal, 102, 603-11. 
11. Martens H. and Naes T. (1989) Multivariate Calibration, Wiley, New York, 1989.

12. Jha S. N. (2007) Journal of Agricultural Engineering, 44(3), 10-14.

13. Tripathi S., Patel K. G. and Bafna A. M. (2010) Journal of Food Science and Technology, 47(6):678-681.
14. Chen Q., Zhao J., Liu M. and Cai J. (2008) Czech Journal of Food Sciences, 26, 360367.

15. Sivakesava S. and Irudayaraj J. (2002) Journal of Dairy Science, 85, 487-493.

16. Yao S., Wu G., Xing M., Zhou S. and Pu J. (2010) Bio Resources, 5, 556-561.

\section{How to cite this article:}

Sonal Tripathi, Narendra Singh, Shailesh Mali, J.R. Naik and Mistry Pritesh, S. 2017. Sugarcane/Sugarcane Juice Quality Evaluation by FT-NIR Spectrometer. Int.J.Curr.Microbiol.App.Sci. 6(9): 3025-3032. doi: https://doi.org/10.20546/ijcmas.2017.609.371 